\title{
Biosimilar Pegfilgrastim: Improving Access and Optimising Practice to Supportive Care that Enables Cure
}

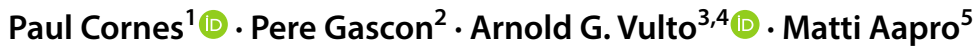

Published online: 30 March 2020

(c) The Author(s) 2020

\begin{abstract}
Febrile neutropenia (FN) is a serious complication of chemotherapy, which can cause significant morbidity and mortality, result in dose delays and reductions and, ultimately, reduce cancer survival. Over the past decade, the availability of biosimilar filgrastim (short-acting granulocyte colony-stimulating factor [G-CSF]) has transformed patient access, with clear evidence of clinical benefit at preventing FN at reduced costs. In 2019, seven biosimilar pegfilgrastims (long-acting G-CSFs) were licensed, creating optimal market conditions and choice for prescribers. FN affects up to 117 per 1000 cancer patients, with mortality rates in the range of $2-21 \%$. By reducing FN incidence and improving chemotherapy relative dose intensity (RDI), G-CSF has been associated with a 3.2\% absolute survival benefit. Guidelines recommend primary prophylaxis and that filgrastim be administered for 10-14 days, while pegfilgrastim is administered once per cycle. When taken according to the guidelines, pegfilgrastim and filgrastim are equally effective. However, in routine clinical practice, filgrastim is often under-dosed ( $<7$ days) and has been shown to be inferior to pegfilgrastim at reducing FN incidence, hospitalisations and maintaining RDI. Once-per-cycle administration with pegfilgrastim might also aid patient adherence. The introduction of biosimilar pegfilgrastim should instigate a rethink of neutropenia management. Biosimilar pegfilgrastim offers countries using biosimilar filgrastim opportunities to improve adherence and thus cancer survival, whilst offering economic benefits for countries using reference pegfilgrastim. These benefits can be realised in full if biosimilar pegfilgrastim becomes part of routine clinical practice supported by drug and therapeutic committees implementing guidelines with multidisciplinary support in the hospital.
\end{abstract}

\section{Introduction}

Febrile neutropenia (FN) is one of the most serious complications of cancer chemotherapy and can lead to fatal consequences, such as sepsis [1]. FN further reduces cancer

Electronic supplementary material The online version of this article (https://doi.org/10.1007/s40259-020-00411-4) contains supplementary material, which is available to authorized users.

Paul Cornes

paul.cornes@yahoo.co.uk

1 Comparative Outcomes Group, Bristol, UK

2 Department of Hematology-Oncology, University of Barcelona, Barcelona, Spain

3 Department of Pharmaceutical and Pharmacological Sciences, KU Leuven, Leuven, Belgium

4 Hospital Pharmacy, Erasmus University Medical Center, Rotterdam, the Netherlands

5 Cancer Center, Clinique de Genolier, Vaud, Switzerland patient survival rates through delays, dose reductions and discontinuations of chemotherapy schedules [2,3]. As well as being a medical emergency with significant clinical burden, the economic burden of FN, particularly related to hospitalisations, is substantial $[4,5]$. Granulocyte colonystimulating factors (G-CSFs) have been proven effective in reducing the incidence of FN and are recommended for the prevention of chemotherapy-induced neutropenia in international guidelines $[1,5]$. There are two main types of G-CSF: filgrastim, which is administered daily during the chemotherapy cycle, and pegfilgrastim, a pegylated form of filgrastim, which allows administration once per cycle [4]. Biosimilars of filgrastim have been available in Europe since 2008 [6]. Biosimilars are lower-cost versions of already authorised reference medicines with comparable physicochemical and biological characterisation and clinical effectiveness and safety [7]. The cost reductions induced by the introduction of biosimilar filgrastim has resulted in increased access to this therapy, with Sweden, for example, documenting a 5-fold increase in reimbursed usage [6]. In 


\section{Key Points}

Pegfilgrastim has been shown to be superior to filgrastim at reducing chemotherapy-related neutropenia and at achieving target dose intensity, as the latter is often under-dosed in clinical practice.

Use of biosimilar pegfilgrastim will facilitate access and, supported by guidelines and clinical rules, enable the full potential of these life-saving benefits to be realised at reduced cost.

New Zealand, expanded use of G-CSF as primary rather than secondary prophylaxis following the introduction of biosimilar filgrastim has seen the number of breast cancer patients hospitalised due to chemotherapy-induced FN decline from one third of women to $<7 \%$ [8]. The first pegfilgrastim biosimilars were approved in Europe in September 2018 and in the US in November that year; there are currently seven such products approved in Europe and three in the US (Table 1). This review aims to explore whether biosimilar pegfilgrastim will have a similar impact to that of biosimilar filgrastim and further improve clinical outcomes and cost effectiveness in patients undergoing cytotoxic chemotherapy.

\section{Methods}

This narrative review was developed by oncologists (MA, PC and PG) and a pharmacist (AV) who are experts in G-CSF and biosimilars and have published widely on the subject matter. Two of the authors (PC and PG) have recently published a systematic review and meta-analysis of all trials of G-CSF or pegfilgrastim for both randomised and nonrandomised comparisons using Cochrane methodology [4]. A further non-systematic review of the relevant literature in PubMed and the Cochrane Library was undertaken, which was supplemented by studies identified by the authors. The importance of G-CSF as primary prophylaxis for chemotherapy-induced neutropenia and the role of pegfilgrastim was summarised and recommendations on the implementation of biosimilar pegfilgrastim provided, predicated on the best available evidence and the authors' experiences with (biosimilar) G-CSF and biosimilars in general.

\section{Burden of Febrile Neutropenia}

$\mathrm{FN}$ is one of the most feared complications of chemotherapy and is classed as a medical emergency [5].

FN is defined by the European Society of Medical Oncology (ESMO) as "an oral temperature of $>38.3{ }^{\circ} \mathrm{C}$ or two

Table 1 Biosimilars of pegfilgrastim approved in Europe and the US

\begin{tabular}{|c|c|c|c|c|}
\hline Brand name & Manufacturer & Registration trial & EMA approval & FDA approval \\
\hline Pelgraz $^{\circledR}$ & Accord Healthcare & $\begin{array}{l}\text { Desai et al. } 2018 \text { [56] } \\
\text { Phase III randomised, assessor-blinded, multicentre study } \\
\text { on } 589 \text { breast cancer patients with reference arms of } \\
\text { US-Neulasta and EU-Neulasta }\end{array}$ & September 2018 & \\
\hline Udenyca $^{\circledR}$ & Coherus & 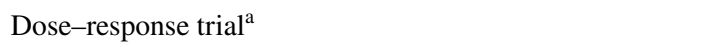 & September 2018 & November 2018 \\
\hline Fulphila $^{\circledR}$ & Mylan & $\begin{array}{l}\text { Waller et al. } 2019 \text { [57] } \\
\text { Phase III randomised, assessor-blinded study on } 194 \\
\text { breast cancer patients with reference arm of } \\
\text { EU-Neulasta }\end{array}$ & November 2018 & June 2018 \\
\hline Pelmeg $^{\circledR}$ & Cinfa Biotech/Mundipharma & Dose-response trial $^{\mathrm{a}}$ & November 2018 & \\
\hline Ziextenzo $^{\circledR}$ & Sandoz & $\begin{array}{l}\text { Harbeck et al. } 2016 \text { [58] } \\
\text { Phase III randomised, assessor-blinded, multicentre study } \\
\text { on } 316 \text { breast cancer patients with reference arm of } \\
\text { EU-Neulasta }\end{array}$ & November 2018 & November 2019 \\
\hline Grasustek $^{\circledR}$ & Juta Pharma & $\begin{array}{l}\text { Grasustek (EPAR) }{ }^{\mathrm{b}} \\
\text { Phase III randomised, assessor-blinded, multicentre study } \\
\text { on } 254 \text { breast cancer patients with reference arm of } \\
\text { EU-Neulasta }\end{array}$ & April 2019 & \\
\hline $\begin{array}{l}\text { Pegfilgrastim } \\
\text { Mundipharma }^{\circledR}\end{array}$ & Mundipharma & Dose-response trial $^{\mathrm{a}}$ & December 2019 & \\
\hline
\end{tabular}

${ }^{a}$ As reported in EMA EPAR available at https://www.ema.europa.eu

${ }^{\text {b} E M A ~ G r a s u s t e k ~ E P A R . ~ A v a i l a b l e ~ a t ~ h t t p s: / / w w w . e m a . e u r o p a . e u / e n / m e d i c i n e s / h u m a n / E P A R / g r a s u s t e k ~}$

EMA European Medicines Agency, EPAR European public assessment report, FDA The Food and Drug Administration 
consecutive readings of $>38.0{ }^{\circ} \mathrm{C}$ for $2 \mathrm{~h}$ and an absolute neutrophil count (ANC) of $<0.5 \times 10^{9} / \mathrm{L}$, or expected to fall below $0.5 \times 10^{9} / \mathrm{L}$ " [5]. It has been estimated that the incidence of FN might be as high as 117 cases per 1000 cancer patients [9]. FN causes a significant medical burden, with up to $30 \%$ of cases requiring inpatient hospital care and mortality rates in the range of $2-21 \%$ [5, 10]. In 2012, the Office of National Statistics reported approximately two deaths per day in England and Wales from neutropenic sepsis [11]. Patients spend an average of 9-10 days in hospital per neutropenic episode $[12,13]$. The economic consequences of FN are substantial, with ESMO estimating in 2016 that the mean cost of an FN hospitalisation in Western countries was approximately $€ 13,500$ [5].

\section{Benefits of Granulocyte Colony-Stimulating Factor (G-CSF) Prophylaxis}

G-CSFs are biological growth factors that stimulate the production, differentiation and activation of neutrophils in the bone marrow, thereby reducing the risk, severity and duration of neutropenia $[2,10]$. A key factor when considering G-CSF is the ANC nadir (the lowest value to which the neutrophil count will fall following drug administration); if the nadir depth and duration can be limited, there are less likely to be complications or chemotherapy dose reductions and delays from neutropenia $[14,15]$. To minimise the ANC nadir, filgrastim is administered as a daily dose of $5 \mu \mathrm{g} / \mathrm{kg}$ at least 24 hours after each chemotherapy administration and within 3-4 days after cycle completion. Pegfilgrastim is given as one 6-mg dose per cycle and should be administered the day after initiating chemotherapy; however, administration up to 3-4 days after initiation may also be reasonable [5, 16-18].

Prophylactic use of G-CSF reduces the incidence of FN and infection-related mortality whilst, importantly, maintaining the relative dose intensity (RDI) of chemotherapy and, thereby, improving cancer outcomes [19, 20]. RDI has a major influence on the efficacy and survival rates of patients receiving chemotherapy for chemo-sensitive tumours. A clear dose-response effect of adjuvant chemotherapy was first demonstrated by Bonadonna and Valagussa in 1981 [21] and confirmed at the 20-year follow-up [22]. In the UK SPROG trial (A Randomised Trial of Secondary Prophylaxis using Granulocyte Colony Stimulating Factor), it was reported that $75 \%$ of patients with breast cancer received their target of $85 \%$ planned RDI of adjuvant chemotherapy with 7 days of filgrastim or pegfilgrastim, compared with only $50 \%$ of those not receiving G-CSF $(p<0.0001)$ [23]. Findings from a meta-analysis provide the most compelling evidence of the importance of G-CSF to cancer outcomes.
In this analysis of data from 61 randomised controlled trials (RCTs) involving 11,337 patients who received G-CSF and 13,456 controls, G-CSF was found to increase absolute cancer survival rates by $3.2 \%$ [24]. To put this into context, this compares with a $2-3 \%$ absolute survival benefit for adjuvant chemotherapy given to early-stage, node-negative breast cancer patients aged 50-69 years [25]. The importance of the impact of G-CSF on long-term cancer outcomes is recognised by its status as a World Health Organization (WHO) Essential Drug, meaning that it should be provided with sufficient reimbursement to be accessed for free, or at prices affordable to all [26].

\section{G-CSF Guidelines}

Established guidelines regarding G-CSF use in the prevention of chemotherapy-induced $\mathrm{FN}$ have been issued by ESMO, the European Organisation for Research and Treatment of Cancer (EORTC), the National Comprehensive Cancer Network (NCCN) and the American Society of Clinical Oncology (ASCO) [1, 5, 16, 17]. G-CSF is recommended as primary prophylaxis of chemotherapy-induced neutropenia when the overall risk of FN for the prescribed regimen is $\geq 20 \%$ (Fig. 1). For patients prescribed chemotherapy with a $10-20 \%$ risk of FN, G-CSF use should be considered in those with additional risk factors placing them at enhanced risk, such as age $>65$ years, coexisting morbidities or prior history of FN. Patients on low-risk regimens $(<10 \%$ risk of $\mathrm{FN})$ are not recommended G-CSF prophylaxis. If primary prophylaxis was not prescribed, G-CSF is recommended as secondary prophylaxis for patients who have had a neutropenic complication from a previous cycle of chemotherapy $[1,5,16,17]$. However, it should be noted that the majority of neutropenic complications occur in the earliest cycles of chemotherapy; for example, across two trials involving high-risk breast cancer patients, the incidence of grade 4 neutropenia in cycle 1 was approximately $80 \%$, but fell to $50 \%$ by cycle $4[14,27]$. Such data emphasises the importance of primary as opposed to secondary G-CSF prophylaxis [28].

Primary prophylaxis with G-CSF should start with the first cycle of chemotherapy and continue throughout subsequent cycles [1, 5, 16, 17]. ESMO recommends administration of filgrastim for around 10 days [5], whilst a recently published expert consensus recommends that pegfilgrastim should always be administered in preference to a duration of daily filgrastim of $<11$ days [9]. Pegfilgrastim use is supported in different length chemotherapy cycles, including fortnightly, albeit data are more limited in patients receiving weekly regimens, where filgrastim might be preferred [9]. For patients on chemotherapy at a high risk of FN $(\geq 20 \%)$ or intermediate risk of FN (10-20\%) plus additional risk 
Fig. 1 Algorithm for assessing FN risk and the need for primary prophylactic G-CSF. Adapted from guidelines by the European Organisation for Research and Treatment of Cancer [1], the European Society of Medical Oncology [5] and the National Comprehensive Cancer Network [16]. $F N$ febrile neutropenia, $G$ - $C S F$ granulocytecolony stimulating factor

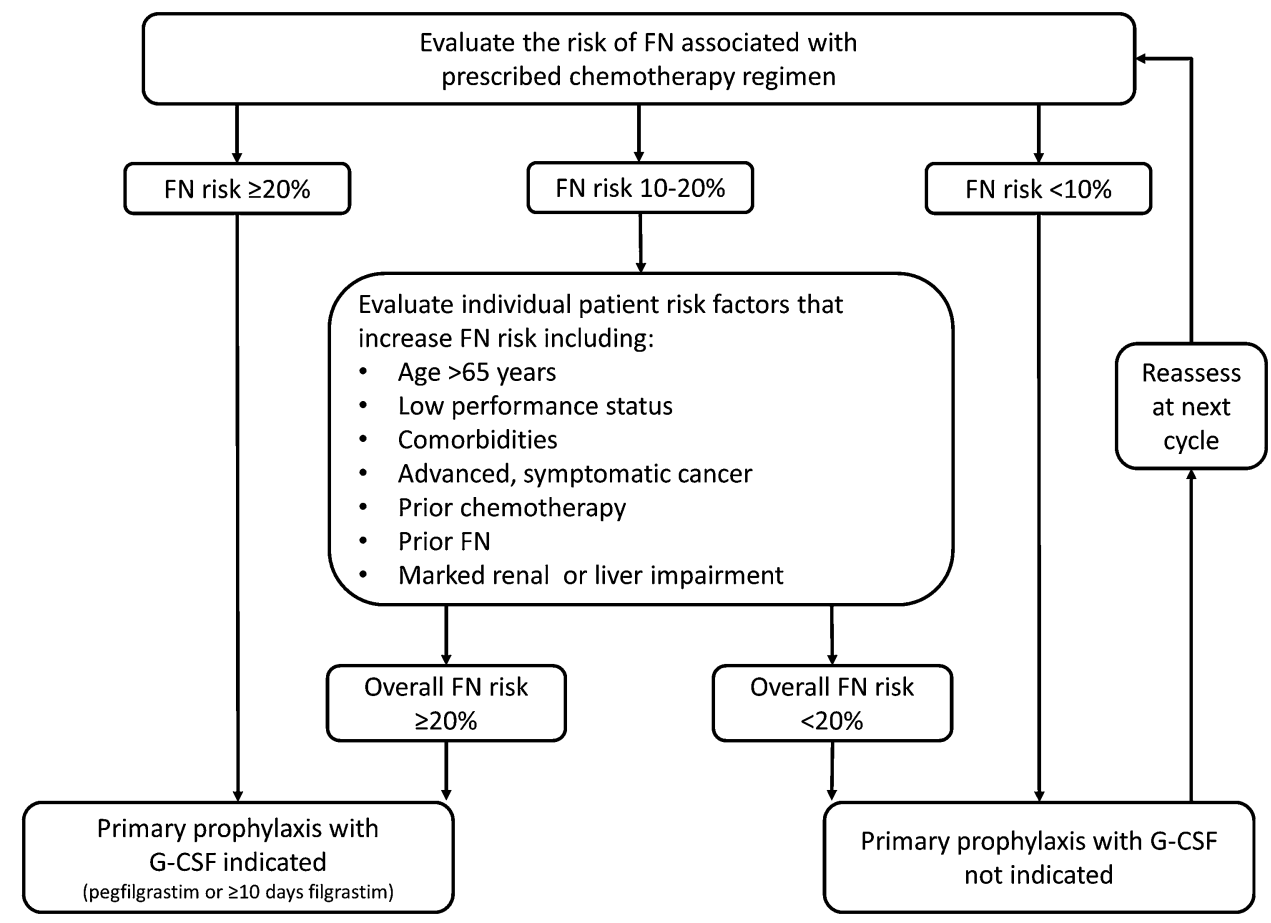

factors, pegfilgrastim is generally considered the G-CSF of choice to maintain RDI and avoid the severe complications associated with FN, due to the simplified administration compared with filgrastim supporting higher adherence and, therefore, coverage of the ANC nadir [9, 29].

The availability of biosimilar pegfilgrastim offers a fresh opportunity to ensure the proper application of these guidelines. A multidisciplinary approach is required both for the implementation of evidenced-based guidelines as well as the adoption of biosimilars into day-to-day practice, and these processes can be linked to mutual benefit. Four key principles can help guide the implementation of biosimilars within a region or country:

1. Multi-stakeholder approach: involve everybody from top to bottom in your healthcare setting and educate about biosimilars.

2. One-voice principle: the whole team should talk about biosimilars in a positive way and avoid sending confused or mixed messages (this will greatly reduce any nocebo effect).

3. Shared decision making: inform the patient about the fact that treatment is initiated/continued with a biosimilar, an equally effective and safe alternative.

4. Gain sharing: introduction of biosimilars requires extra effort (=time) from busy healthcare professionals. A part of the savings from biosimilars should benefit the clinical department that generate the savings.
This process, for example, could be led by a pharmacist, involving presentations and discussions with the oncology physicians and nursing staff. Computer order systems for anticancer therapies could be leveraged to link biosimilar pegfilgrastim to chemotherapy regimens with a high risk of FN. In this way, implementation of the G-CSF guidelines can be assured as well as the adoption of biosimilar pegfilgrastim into routine practice. It cannot be overstressed the importance that all healthcare professionals involved in the care of cancer patients are in agreement about when to use G-CSF support and the use of biosimilar pegfilgrastim to ensure an efficient and long-term solution. The use of clinical rules, whereby pharmacists work collaboratively with physicians to ensure guidelines are implemented, will support and facilitate this.

\section{Pegfilgrastim Versus Filgrastim}

Numerous studies have compared the efficacy and safety of pegfilgrastim and filgrastim [4, 15, 30-32]. A recent metaanalysis identified 36 studies that reported a direct, headto-head comparison of pegfilgrastim versus filgrastim [4]. In 12 RCTs, the relative risk (RR) of developing FN was lower for pegfilgrastim compared with filgrastim, but the difference was not statistically significant $(0.86 ; p=0.226)$. Importantly, however, in 24 non-RCTs, the overall risk was significantly lower with pegfilgrastim than filgrastim for the incidence of FN (RR $0.67 ; p=0.023$ ), FN-related 
hospitalisations (RR $0.68 ; p<0.05)$ and chemotherapy dose delays (RR $0.68 ; p=0.020$ ). It was postulated by the authors that the greater efficacy of pegfilgrastim in non-RCTs might reflect under-dosing of filgrastim in routine clinical practice, as reflected in 11 of 12 RCTs that administered seven or more doses of short-acting G-CSF versus only 2 of 24 non-RCTs [4]. When dosed equivalently (one dose of pegfilgrastim and 10-14 days of filgrastim), the safety profiles (e.g. bone pain) have been shown to be similar [31].

Several studies have reported that under-dosing of filgrastim is prevalent in routine clinical practice [33-37]. Under-dosing of filgrastim has been reported in $17.4 \%$ of patients in Europe [37], with the median schedule used being only 5 days [38]. Under-dosing by weight is also common practice, with a German study reporting that approximately three-quarters of patients received the 300- $\mu \mathrm{g}$ (30-MU) dose of filgrastim (recommended for body weight up to $60 \mathrm{~kg}$ ), when the average body weight (in Germany) is $75.6 \mathrm{~kg}$ [35].

There are a number of possible reasons for the widespread under-dosing of filgrastim. A key reason is likely to be that filgrastim has always been available in a pack of five and from the earliest days of its use, patients were often prescribed one pack of $300 \mu \mathrm{g}$ for reasons of cost and convenience. Although the advent of biosimilar filgrastim has removed or at least significantly diminished the cost element, it appears to still be habitual practice to prescribe a single pack of five [35]. A survey of healthcare professionals (HCPs) from six European countries (Germany, Italy, Portugal, Poland, Lithuania and Latvia) undertaken in early 2019 to support this review found that almost half $(48 \%$; 42/88) of HCPs ( $89 \%$ physicians; $11 \%$ pharmacists) did not follow weight-based dosing of filgrastim and nearly two-thirds (64\%; 56/88) prescribed a course of $<7$ days (Fig. 2). The reason is fundamentally simple: physician and pharmacist co-responsibility for proper use has not been implemented in the majority of hospitals. Patient adherence with the filgrastim regimen is another potentially salient reason for under-dosing. Lack of physician familiarity or awareness of the G-CSF guidelines and/or the consequences of FN on RDI and, thereby, cancer survival is likely to be another factor behind under-dosing of filgrastim and under use of G-CSF in general [39-41]. In Germany, for example, despite $85.1 \%$ of 195 physicians stating that they followed G-CSF guidelines, evidence revealed only $15.4 \%$ adherence for high-risk lung cancer patients and $<50 \%$ for intermediaterisk lung and breast cancer patients [41]. Lack of risk factors was cited by over half the physicians as a reason for not using G-CSF in patients prescribed a chemotherapy with a FN risk $\geq 20 \%$ [41], yet the assessment of risk factors in this group of patients is unnecessary and only required for intermediate- or low-risk groups $[1,5,16]$. Overall, it has been reported that as many as $80 \%$ of patients do not receive primary prophylaxis with G-CSF in accordance with their assessed risk [39, 41]. Dose reductions of chemotherapy related to neutropenia and use of G-CSF only as secondary prophylaxis have also been found to be widespread in clinical practice $[39,41]$.
Fig. 2 European survey results highlighting the under-dosing of filgrastim by both weight and duration of therapy. The survey of 88 healthcare professionals (78 physicians; 10 pharmacists) from six European countries (Germany $n=3$; Italy $n=7$; Portugal $n=31$; Poland $n=29$; Lithuania $n=12$; Latvia $n=6$ ) was undertaken in April-May 2019. Respondents were based in oncology clinics $(n=3)$; general hospitals $(n=36)$; or specialist haematology or oncology centres $(n=48)$. HCPs healthcare professionals

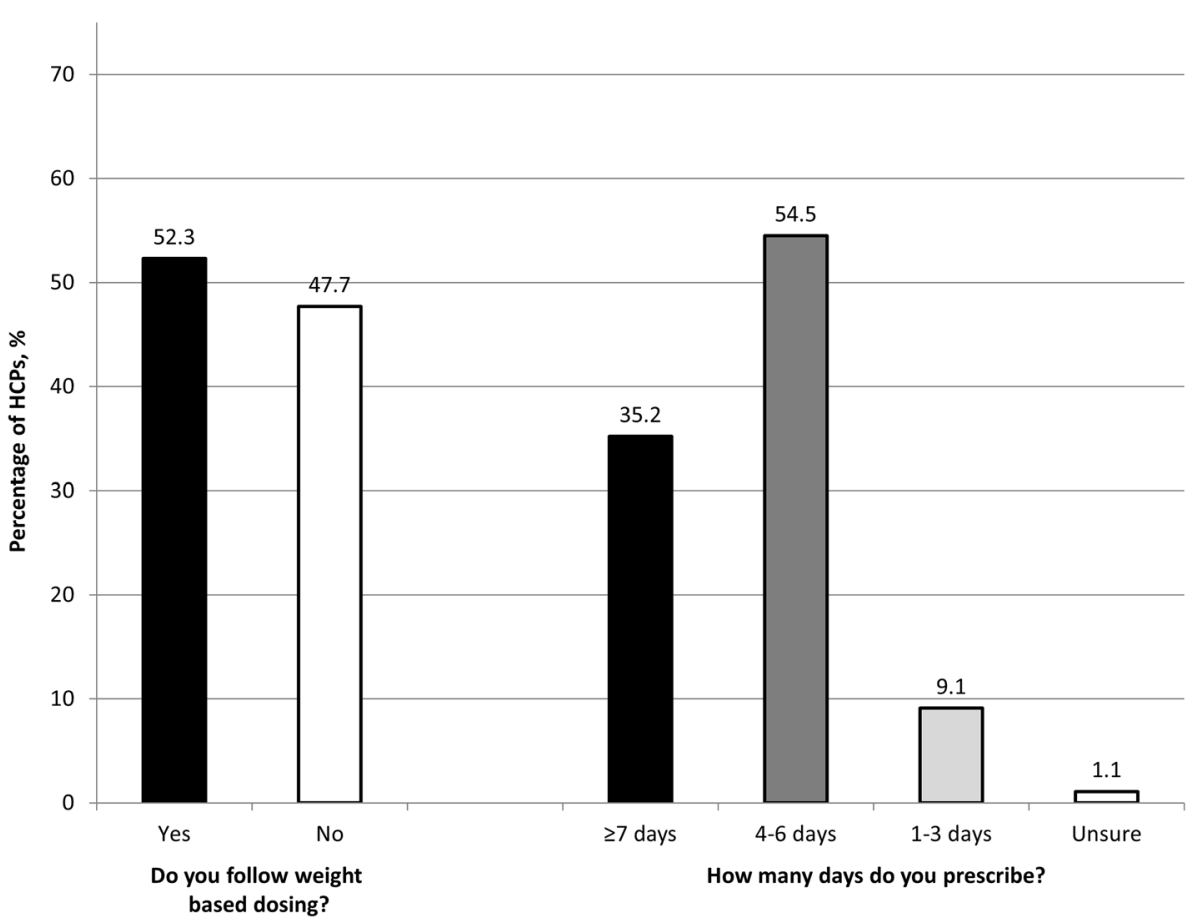


This widespread reporting of under-dosing (by weightadapted dose and duration of therapy), with lack of adherence to both prescribing guidelines and the approved drug label for G-CSF, is striking. Given the proven impact of filgrastim on cancer cure, it is hard to imagine that such a situation would be considered appropriate for other aspects of curative cancer treatment, such as radiation or chemotherapy doses and schedules [24].

Awareness and adherence to G-CSF guidelines can be improved through educational workshops, training courses and lectures, as demonstrated in Germany, where such interventions increased G-CSF use in alignment with guidelines from 15.4 to $47.8 \%$ in high-risk FN lung cancer patients undergoing chemotherapy [42]. Whilst initiatives such as this represent a good start, more still needs to be done as adherence rates of $<50 \%$ remain unacceptable, since this can jeopardise patient survival by increasing the risk of hospitalisations with neutropenic complications and the likelihood of interruptions to or discontinuation of chemotherapy treatment. The goal is to change practice in the long term and this requires a multidisciplinary approach with multiple forms of interventions. One of the most successful strategies to improve clinical practice and quality of care are clinical rules, whereby pharmacists support physicians by ensuring complete execution of a clinical protocol, such as the addition of laxatives when prescribing opioids. A concerted, pan-European programme, driven by a key society such as ESMO together with the European Association of Hospital Pharmacists (EAHP) and supported by individual country initiatives or national associations, is recommended to maximise the potential of G-CSF therapy to improve cancer cure rates and survival.

Pegfilgrastim offers distinct advantages over filgrastim in supporting adherence to G-CSF guidelines and in helping to ensure patients obtain sufficient G-CSF coverage during their chemotherapy. As a single 6-mg dose per cycle, pegfilgrastim obviates any weight-based dosing errors and insufficient duration of use that can occur with filgrastim [4, 5]. In addition, the once-per-cycle administration of pegfilgrastim may increase patient adherence, as the need for daily administration, daily hospital visits and regular testing of ANC levels is eliminated [9]. Fewer hospital visits might also improve patient quality of life, particularly for older or frail patients, and reduce the risk of nosocomial infections, as well as saving the associated hospital resource use. Adherence to G-CSF guidelines has been shown to be higher with pegfilgrastim than filgrastim. In an Italian observational study of 645 consecutive patients and 3150 chemotherapy administrations, it was revealed that physicians were more likely to follow guidelines with pegfilgrastim compared with short-acting G-CSF ( $66 \%$ vs $47 \%$, respectively; $p=0.002$ ) [43]. Furthermore, pegfilgrastim was administered at the correct time in $93.2 \%$ of patients compared with only
$61.5 \%$ of patients receiving short-acting G-CSF $(p<0.0001)$ [43]. There is also some evidence that pegfilgrastim might improve RDI of chemotherapy compared with filgrastim. In the SPROG trial, $84.9 \%$ of breast cancer patients who received pegfilgrastim as secondary prophylaxis achieved $85 \%$ planned RDI of adjuvant chemotherapy compared with $69.5 \%$ of patients on 7 days of filgrastim (no $p$ value reported) [23].

\section{Assessing the Value of Biosimilar Pegfilgrastim}

As cancer incidence continues to rise and the costs of novel therapies ever increase, the need to find cheaper but equally effective therapies is paramount for the sustainability of healthcare systems. Biosimilars are as clinically effective as reference products and can be $>30 \%$ cheaper, with cumulative savings across the five major European Union (EU) markets and the US estimated to reach $€ 50-100$ billion between 2016 and 2020 [44]; creating headroom in healthcare budgets for new medicines. Since 2006, 58 biosimilars have been approved in Europe, including six biosimilars of filgrastim [45]. As a result of the introduction of biosimilars, access to biologics has increased by as much as $100 \%$ in the EU [44]. Initial concerns surrounding the efficacy and safety of biosimilars and the risks surrounding extrapolation of data and immunogenicity have proven to be completely unfounded $[6,46,47]$. In a decade of use, biosimilar filgrastim has proven to be equally as effective and well tolerated as reference filgrastim, whilst providing cost savings (conservatively estimated to be $39 \%$ in Europe), increased access and a resultant decrease in FN-related hospitalisations [6, 8, 48, 49]. The recent licensing in Europe of seven biosimilar pegfilgrastim-containing products (as of December 2019) offers the opportunity to deliver the additional advantages of long- over short-acting G-CSF at a reduced cost. Biosimilar pegfilgrastim costs approximately $€ 650$ and filgrastim $€ 100$ per dose (based on list prices in the UK and France) [50, 51], meaning that at least six or seven doses of biosimilar filgrastim need to be prescribed to achieve price parity (with the caveat that any local or regional discounts etc. may affect this ratio). Hence, different approaches to adoption of biosimilar pegfilgrastim may be required depending on whether a country/jurisdiction is using predominantly reference pegfilgrastim or biosimilar filgrastim.

For countries using predominantly filgrastim biosimilars, the advantages of biosimilar pegfilgrastim are manifest in the simplified once-per-cycle dosing; improving adherence and appropriate coverage of the ANC nadir, and, thereby, fewer neutropenic events and FN-related deaths, increased RDI and improved cancer survival. All countries currently using filgrastim are urged to audit current usage to determine 
Table 2 Key clinical and economic benefits offered by biosimilar pegfilgrastim

\begin{tabular}{ll}
\hline Clinical benefits vs filgrastim ( $<7$ days $)$ & Economic benefits vs reference pegfilgrastim \\
\hline Reduced FN incidence & Cost savings $>30 \%$ \\
Reduced FN-related hospitalisations & Increased patient access \\
Reduced chemotherapy dose delays & Create additional budget for new medicines \\
Improved relative dose intensity & Financial sustainability \\
Improved adherence to G-CSF guidelines & Improved device/additional handling features \\
Reduced hospital visits and risk of nosocomial infections & \\
Improved patient acceptability and adherence &
\end{tabular}

$F N$ febrile neutropenia, $G$ - $C S F$ granulocyte colony-stimulating factors

if under-dosing is commonplace, by number of doses and/ or weight, and the implications of this on planned chemotherapy schedules and RDI (See Online Resource 1 in the electronic supplementary material for a suggested minimum dataset). Data from such audits should be taken into account when considering the relative costs versus benefits of biosimilar pegfilgrastim and biosimilar filgrastim. If a country is using the appropriate dosage of filgrastim (10-14 days), it may be that direct cost savings can be achieved with the introduction of biosimilar pegfilgrastim (e.g. $€ 1000-€ 1400$ vs $€ 650$ per cycle, respectively, using the prices quoted above).

For countries currently using reference pegfilgrastim, there are evident cost savings to be made of $>30 \%$ or more by switching to biosimilar pegfilgrastim, which could support increased access to this important therapy and/or free up additional funds in the cancer drugs budget [44]. The introduction of biosimilar pegfilgrastim will also increase competition in those countries using predominantly lipegfilgrastim, a second-in-class long-acting G-CSF.

In terms of choice of biosimilar pegfilgrastim, competition between manufacturers will likely result in the products being priced similarly, as is seen with biosimilars in other therapeutic areas. Assuming price parity, the choice of biosimilar may come down to a choice of device, as this can have a potentially strong influence on adherence. It is well known across all areas of medicine that patient anxiety and fear of needles can lead to poor adherence [52-54]. The biosimilar pegfilgrastim considered to have the most easy-touse device, for example, with a shorter and smaller diameter or hidden needles, would likely lead to improved adherence [54]. Processes to ensure that the rubber plunger does not stiffen with age and increase friction and, thereby, cause problems with delivery of the full dose are also a key consideration [55]. A simple, patient-friendly device would likely increase patients' willingness to self-administer at home, as well as increase the efficiency of nurse delivery; which could provide further cost savings. Improving adherence to G-CSF therapy, and thereby optimising chemotherapy treatment and improving outcomes, could result in substantial savings in the cost of disease management and should be considered when deciding upon which pegfilgrastim biosimilar to prescribe.

\section{Conclusions}

Primary prophylaxis with G-CSF for patients on high-risk $(\geq 20 \%)$ chemotherapies, or those on intermediate-risk (10-20\%) chemotherapies plus additional risk factors, is critical to improving cancer patient survival by ensuring dose intensity of cancer therapy is maintained. It would be unacceptable for patients not to receive their full course of adjuvant radiotherapy, and the same standard should apply for chemotherapy. In clinical practice, the use of pegfilgrastim has been shown to be clinically superior to filgrastim at reducing neutropenic events and FN [4], improving adherence to G-CSF guidelines [43] and at achieving target RDI [23], as the latter is frequently under-dosed [4, 36, 37]. Biosimilar pegfilgrastim offers a fresh opportunity to rethink neutropenia management and the value of G-CSF in 2020, based on the significant potential for both clinical and economic benefits (Table 2). A concerted, multidisciplinary action, involving prescribing physicians, oncology nurses and pharmacists, supported by guidelines and clinical rules, will release the full potential of this life-saving strategy.

Acknowledgements Writing and editorial support was provided by Barry Rodgers-Gray, Strategen Limited, Basingstoke, UK.

Author Contributions All authors contributed to the review of the evidence and development of the consensus opinion. All authors contributed and agreed to the outline for the manuscript. The first draft was edited by PC and all authors commented on previous versions of the manuscript. All authors read and approved the final manuscript. PC is guarantor for the overall content.

\section{Compliance with Ethical Standards}

Funding This work was supported by Accord Healthcare, which provided funding to Strategen Limited for editorial services in relation to the production of this article. Accord had no input into the editorial 
content or the final article. The statements, findings, conclusions, views and opinions contained and expressed herein are not necessarily those of Accord or any of its affiliated or subsidiary entities. Accord provided funding for Open Access.

Conflict of interest The authors received no financial support for the development of this article. Paul Cornes declares honorarium or support for attending meetings from Accord Healthcare, Amgen, Astro Pharma, European Association for Hospital Pharmacists, European Commission, Medicines for Europe/European Generics Association, Medscape, Mylan, Napp, Pfizer/Hospira, Sandoz and Teva. Pere Gascon declares honorarium and support for attending meetings/lecturing from Accord Healthcare, Amgen, Sandoz and Pfizer/Hospira. Arnold G. Vulto has conducted biosimilar research sponsored by Hospira (now Pfizer) and declares honorarium or support for consulting, advisory work and speaking engagements from AbbVie, Accord Healthcare, Amgen, Biogen, Fresenius-Kabi, Medicines for Europe, Pfizer/ Hospira, Mundipharma, Roche and Sandoz. Matti Aapro declares received honoraria and/or consultant support from Accord Healthcare, Amgen, Bayer, BMS, Celgene, Cephalon, Chugai, Clinigen, Eisai, GenomicHealth, GSK, Helsinn, Hospira, Ipsen, J\&J, Kyowa, Merck, Novartis, OrthoBiotech, Pfizer, PierreFabre, Roche, Sandoz, Sanofi, Tesaro, Taiho, Teva and Vifor.

Open Access This article is licensed under a Creative Commons Attribution-NonCommercial 4.0 International License, which permits any non-commercial use, sharing, adaptation, distribution and reproduction in any medium or format, as long as you give appropriate credit to the original author(s) and the source, provide a link to the Creative Commons licence, and indicate if changes were made. The images or other third party material in this article are included in the article's Creative Commons licence, unless indicated otherwise in a credit line to the material. If material is not included in the article's Creative Commons licence and your intended use is not permitted by statutory regulation or exceeds the permitted use, you will need to obtain permission directly from the copyright holder.To view a copy of this licence, visit http://creativecommons.org/licenses/by-nc/4.0/.

\section{References}

1. Aapro MS, Bohlius J, Cameron DA, et al. 2010 update of EORTC guidelines for the use of granulocyte-colony stimulating factor to reduce the incidence of chemotherapy-induced febrile neutropenia in adult patients with lymphoproliferative disorders and solid tumours. Eur J Cancer. 2011;47:8-32.

2. Wang L, Baser O, Kutikova L, et al. The impact of primary prophylaxis with granulocyte colony-stimulating factors on febrile neutropenia during chemotherapy: a systematic review and metaanalysis of randomized controlled trials. Support Care Cancer. 2015;23:3131-40.

3. Bonadonna G, Moliterni A, Zambetti M, et al. 30 years' follow up of randomised studies of adjuvant CMF in operable breast cancer: cohort study. BMJ. 2005;330:217.

4. Cornes P, Gascon P, Chan S, et al. Systematic review and metaanalysis of short- versus long-acting granulocyte colony-stimulating factors for reduction of chemotherapy-induced febrile neutropenia. Adv Ther. 2018;35:1816-29.

5. Klastersky J, de Naurois J, Rolston K, et al. Management of febrile neutropaenia: ESMO Clinical Practice Guidelines. Ann Oncol. 2016;27:v111-8.

6. Gascón P, Tesch H, Verpoort K, et al. Clinical experience with Zarzio ${ }^{\circledR}$ in Europe: what have we learned? Support Care Cancer. 2013;21:2925-32.
7. European Commission What you need to know about biosimilar medicinal products - a consensus information document. 2013. https://ec.europa.eu/docsroom/documents/8242/attachments/1/ translations/en/renditions/pdf. Accessed 01 June 2019.

8. PHARMAC. Filgrastim change-a view from the front line. https ://www.pharmac.govt.nz/medicines/new-medicines/medicinepricing/biosimilar-filgrastim-2/filgrastim-sidebar-2/ Accessed 02 Jan 2020.

9. Aapro M, Boccia R, Leonard R, et al. Refining the role of pegfilgrastim (a long-acting G-CSF) for prevention of chemotherapyinduced febrile neutropenia: consensus guidance recommendations. Support Care Cancer. 2017;25:3295-304.

10. National Institute for Health and Care Excellence. Neutropenic sepsis: prevention and management in people with cancer (CG151). 2012. https://www.nice.org.uk/guidance/cg151. Accessed 01 June 2019.

11. National Collaborating Centre for Cancer. Neutropenic sepsis: prevention and management of neutropenic sepsis in cancer patient. London: National Institute for Health and Clinical Excellence (UK); 2012. Available from: https://www.ncbi.nlm.nih.gov/books /NBK299128/.

12. Schelenz S, Giles D, Abdallah S. Epidemiology, management and economic impact of febrile neutropenia in oncology patients receiving routine care at a regional UK cancer centre. Ann Oncol. 2012;23:1889-93.

13. Tai E, Guy GP, Dunbar A, Richardson LC. Cost of cancer-related neutropenia or fever hospitalizations, United States, 2012. J Oncol Pract. 2017;13:e552-61.

14. Crawford J, Ozer H, Stoller R, et al. Reduction by granulocyte colony-stimulating factor of fever and neutropenia induced by chemotherapy in patients with small-cell lung cancer. N Engl J Med. 1991;18(325):164-70.

15. Green MD, Koelbl H, Baselga J, et al. A randomized double-blind multicenter phase III study of fixed-dose single-administration pegfilgrastim versus daily filgrastim in patients receiving myelosuppressive chemotherapy. Ann Oncol. 2003;14:29-35.

16. Crawford J, Becker PS, Armitage JO, et al. Myeloid growth factors, Version 2.2017, NCCN Clinical Practice Guidelines in Oncology. J Natl Compr Canc Netw. 2017;15:1520-41.

17. Smith TJ, Bohlke K, Lyman GH, et al. Recommendations for the use of WBC growth factors: American Society of clinical oncology clinical practice guideline update. J Clin Oncol. 2015;33:3199-212.

18. Crawford J, Caserta C, Roila F, ESMO Guidelines Working Group. Hematopoietic growth factors: ESMO Clinical Practice Guidelines for the applications. Ann Oncol. 2010;21:v248-51.

19. Kuderer NM, Dale DC, Crawford J, Lyman GH. Impact of primary prophylaxis with granulocyte colony-stimulating factor on febrile neutropenia and mortality in adult cancer patients receiving chemotherapy: a systematic review. J Clin Oncol. 2007;25:3158-67.

20. von Minckwitz G, Kümmel S, du Bois A, et al. Pegfilgrastim \pm ciprofloxacin for primary prophylaxis with TAC (docetaxel/ doxorubicin/cyclophosphamide) chemotherapy for breast cancer. Results from the GEPARTRIO study. Ann Oncol. 2008;19:292-8.

21. Bonadonna G, Valagussa P. Dose-response effect of adjuvant chemotherapy in breast cancer. N Engl J Med. 1981;304:10-5.

22. Bonadonna G, Valagussa P, Moliterni A, et al. Adjuvant cyclophosphamide, methotrexate, and fluorouracil in node-positive breast cancer: the results of 20 years of follow-up. N Engl J Med. 1995;332:901-6.

23. Leonard RC, Mansi JL, Keerie C, et al. A randomised trial of secondary prophylaxis using granulocyte colony-stimulating factor ('SPROG' trial) for maintaining dose intensity of standard adjuvant chemotherapy for breast cancer by the Anglo-Celtic Cooperative Group and NCRN. Ann Oncol. 2015;26:2437-41. 
24. Lyman GH, Dale DC, Culakova E, et al. The impact of the granulocyte colony-stimulating factor on chemotherapy dose intensity and cancer survival: a systematic review and meta-analysis of randomized controlled trials. Ann Oncol. 2013;24:2475-84.

25. Early Breast Cancer Trialists' Collaborative Group (EBCTCG). Polychemotherapy for early breast cancer: an overview of the randomised trials. Early Breast Cancer Trialists' Collaborative Group. Lancet. 1998;352:930-42.

26. The World Health Organization. The selection and use of essential medicines: report of the WHO Expert Committee (WHO technical report series 1006). 2017. https://www.who.int/medicines/publicatio ns/essentialmedicines/trs-1006-2017/en/. Accessed 01 June 2019.

27. Holmes FA, O'Shaughnessy JA, Vukelja S, et al. Blinded, randomized, multicenter study to evaluate single administration pegfilgrastim once per cycle versus daily filgrastim as an adjunct to chemotherapy in patients with high-risk stage II or stage III/IV breast cancer. J Clin Oncol. 2002;20:727-31.

28. Crawford J, Dale DC, Lyman GH. Chemotherapy-induced neutropenia: risks, consequences, and new directions for its management. Cancer. 2004;100:228-37.

29. Lambertini M, Ferreira AR, Del Mastro L, et al. Pegfilgrastim for the prevention of chemotherapy-induced febrile neutropenia in patients with solid tumors. Expert Opin Biol Ther. 2015;15:1799-817.

30. Holmes FA, Jones SE, O'Shaughnessy J, et al. Comparable efficacy and safety profiles of once-per-cycle pegfilgrastim and daily injection filgrastim in chemotherapy-induced neutropenia: a multicenter dose-finding study in women with breast cancer. Ann Oncol. 2002;13:903-9.

31. Grigg A, Solal-Celigny P, Hoskin P, et al. Open-label, randomized study of pegfilgrastim vs. daily filgrastim as an adjunct to chemotherapy in elderly patients with non-Hodgkin's lymphoma. Leuk Lymphoma. 2003;44:1503-8.

32. Bond TC, Szabo E, Gabriel S, et al. Meta-analysis and indirect treatment comparison of lipegfilgrastim with pegfilgrastim and filgrastim for the reduction of chemotherapy-induced neutropeniarelated events. J Oncol Pharm Pract. 2018;24:412-23.

33. Almenar D, Mayans J, Juan O, et al. Pegfilgrastim and daily granulocyte colony-stimulating factor: patterns of use and neutropenia-related outcomes in cancer patients in Spain-results of the LEARN Study. Eur J Cancer Care. 2009;18(3):280-6.

34. Almenar Cubells D, Bosch Roig C, Jiménez Orozco E, et al. Effectiveness of daily versus non-daily granulocyte colony-stimulating factors in patients with solid tumours undergoing chemotherapy: a multivariate analysis of data from current practice. Eur J Cancer Care. 2013;22:400-12.

35. Hadji P, Kostev K, Schröder-Bernhardi D, Ziller V. Cost comparison of outpatient treatment with granulocyte colony-stimulating factors (G-CSF) in Germany. Int J Clin Pharmacol Ther. 2012;50:281-9.

36. Weycker D, Barron R, Edelsberg J, et al. Risk and consequences of chemotherapy-induced neutropenic complications in patients receiving daily filgrastim: the importance of duration of prophylaxis. BMC Health Serv Res. 2014;14:189.

37. Gascon P, Aapro M, Ludwig H, et al. Treatment patterns and outcomes in the prophylaxis of chemotherapy-induced (febrile) neutropenia with biosimilar filgrastim (the MONITOR-GCSF study). Support Care Cancer. 2016;24:911-25.

38. Aapro M, Cornes P, Abraham I. Comparative cost-efficiency across the European G5 countries of various regimens of filgrastim, biosimilar filgrastim, and pegfilgrastim to reduce the incidence of chemotherapy-induced febrile neutropenia. J Oncol Pharm Pract. 2012;18:171-9.

39. Barnes G, Pathak A, Schwartzberg L. G-CSF utilization rate and prescribing patterns in United States: associations between physician and patient factors and GCSF use. Cancer Med. 2014;3:1477-84.
40. Krzemieniecki K, Sevelda P, Erdkamp F, et al. Neutropenia management and granulocyte colony-stimulating factor use in patients with solid tumours receiving myelotoxic chemotherapy-findings from clinical practice. Support Care Cancer. 2014;22:667-77.

41. Link H, Nietsch J, Kerkmann M, et al. Adherence to granulocyte-colony stimulating factor (G-CSF) guidelines to reduce the incidence of febrile neutropenia after chemotherapy-a representative sample survey in Germany. Support Care Cancer. 2016;24:367-76.

42. Link H, Kerkmann M, Holtmann L, et al. G-CSF guideline adherence in Germany, an update with a retrospective and representative sample survey. Support Care Cancer. 2019;27:1459-69.

43. Fagnani D, Isa L, Verga MF, et al. Granulocyte colony-stimulating factors used in clinical practice: PoloNord registry-based cohort Italian study. Tumori. 2014;100:491-8.

44. IMS Institute for Healthcare Informatics. Delivering on the potential of biosimilar medicines. 2016. Available from: https://www. medicinesforeurope.com/wp-content/uploads/2016/03/IMS-Insti tute-Biosimilar-Report-March-2016-FINAL.pdf.

45. Generics and Biosimilars Initiative (GABI). Biosimilars approved in Europe. www.gabionline.net/Biosimilars/General/Biosimilar s-approvedin-Europe. Accessed 01 June 2019.

46. Weise M, Bielsky MC, De Smet K, et al. Biosimilars: what clinicians should know. Blood. 2012;120:5111-7.

47. Cohen HP, Blauvelt A, Rifkin RM, et al. Switching reference medicines to biosimilars: a systematic literature review of clinical outcomes. Drugs. 2018;78:463-78.

48. Schwartzberg LS, Lal LS, Balu S, et al. Clinical outcomes of treatment with filgrastim versus a filgrastim biosimilar and febrile neutropenia-associated costs among patients with nonmyeloid cancer undergoing chemotherapy. J Manag Care Spec Pharm. 2018;24:976-84.

49. IQVIA. The impact of biosmilar competition in Europe. September 2018. Available from: https://ec.europa.eu/docsroom/docum ents/31642/attachments/1/translations/en/renditions/pdf.

50. Assurance maladie en France 2018. https://www.ameli.fr/etabl issement-de-sante/exercice-professionnel/nomenclatures-codag e/medicaments. Accessed 06 Jan 2020.

51. British National Formulary (BNF). https://bnf.nice.org.uk/. Accessed 06 Jan 2020.

52. de Jong ME, Carbière T, van den Heuvel-Eibrink MM. The use of an insuflon device for the administration of G-CSF in pediatric cancer patients. Support Care Cancer. 2006;14:98-100.

53. Schiff M, Saunderson S, Mountian I, Hartley P. Chronic disease and self-injection: ethnographic investigations into the patient experience during treatment. Rheumatol Ther. 2017;4:445-63.

54. McLenon J, Rogers MAM. The fear of needles: a systematic review and meta-analysis. J Adv Nurs. 2019;75:30-42.

55. Kasem H, Shriki H, Ganon L, et al. Rubber plunger surface texturing for friction reduction in medical syringes. Friction. 2019. https ://doi.org/10.1007/s40544-018-0227-5.

56. Desai K, Misra P, Kher S, Shah N. Clinical confirmation to demonstrate similarity for a biosimilar pegfilgrastim: a 3-way randomized equivalence study for a proposed biosimilar pegfilgrastim versus US-licensed and EU-approved reference products in breast cancer patients receiving myelosuppressive chemotherapy. Exp Hematol Oncol. 2018;7:22.

57. Waller CF, Ranganna GM, Pennella EJ, et al. Randomized phase 3 efficacy and safety trial of proposed pegfilgrastim biosimilar MYL-1401H in the prophylactic treatment of chemotherapyinduced neutropenia. Ann Hematol. 2019;98:1217-24.

58. Harbeck N, Lipatov O, Frolova M, et al. Randomized, double-blind study comparing proposed biosimilar LA-EP2006 with reference pegfilgrastim in breast cancer. Future Oncol. 2016;12:1359-67. 